\title{
Dynamic compression bone clamp for transverse fractures
}

\author{
Donald H Lalonde BSc MSc MD FRCSC \\ Saint John Regional Hospital, Dalhousie University, Saint John Campus, Saint John, New Brunswick
}

DH Lalonde. Dynamic compression bone clamp for transverse fractures. Can J Plast Surg 2000;8(2):78-80.

\begin{abstract}
A bone clamp with the following important features is described: it provides a dynamic compression force to transversely fractured bone ends before they are fixed with internal hardware; it is designed to reduce transverse bone fractures; and it holds the bone with sharp, opposing points like a towel clip.
\end{abstract}

Key Words: Bone clamp; Dynamic compression; Transverse fracture

\section{Compression dynamique à l'aide d'un clamp à os pour les fractures transverses}

RÉSUMÉ: Voici la description d'une pince à os possédant des caractéristiques importantes : elle permet d'exercer une force de compression dynamique sur les bouts d'os fracturés transversalement avant leur immobilisation à l'aide de dispositifs internes, de réduire les fractures transverses et de maintenir en place l'os à l'aide de dents pointues, opposées, comme une pince à champ.

$\mathrm{D}$ ynamic compression of bone fragments has been found to provide a beneficial effect on bone healing (1). Until now, the only ways of providing dynamic compression to two bone fragments have been

dynamic compression plating, some forms of external fixation, and manually pushing the two bone ends together before internally fixing them.

The sharp teeth of the bone clamp described herein are built in such a way that the bone clamp itself delivers a dy-

Correspondence: Dr Don Lalonde, 705 Millidge Avenue, Saint John, New Brunswick E2K 2N7. Telephone 506-648-7950, fax 506-652-8042, e-mailhuzil@health.nb.ca

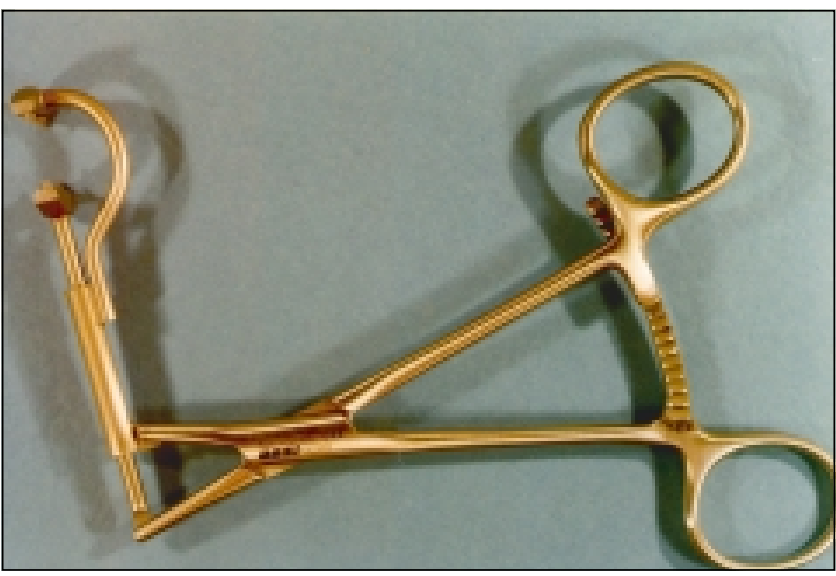

Figure 1) The dynamic compression transverse fracture bone clamp 


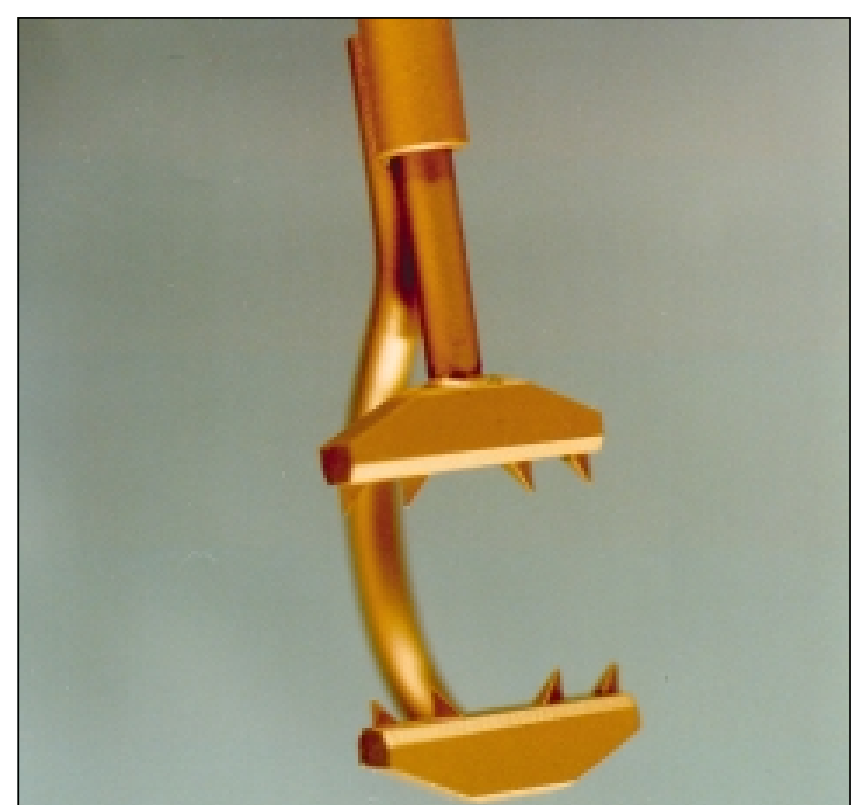

Figure 2) Oblique view of the teeth. As the teeth bite into the bone, the bone slides down the flat, sloping, medial triangular tooth surface and is driven medially

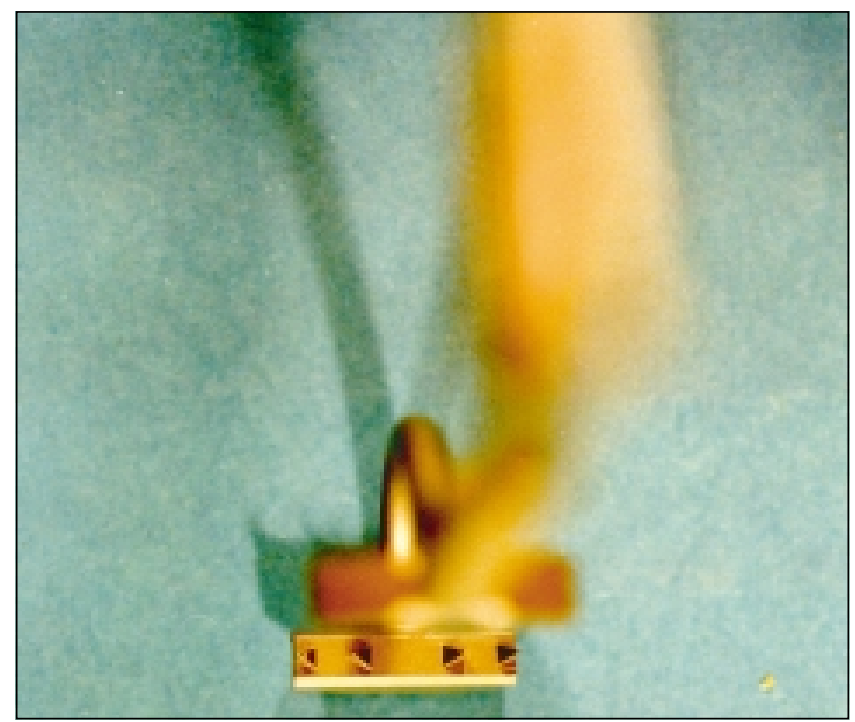

Figure 3) View of the teeth from the bone's perspective. As the tooth bites into the bone, the sharp lateral tooth edge cuts into the advancing bone, away from the fracture, allowing the sloping medial tooth to push the fractured bone medially

namic compression force to the two bone ends before they are internally fixed.

One of the most commonly used instruments for the reduction of bone fractures is the towel clip. This is because the two ends of the towel clip are sharp and do not release the bone once they are applied.

A bone clamp built in the 1990s simulated the action of the towel clip with two sharp points (2). This bone clamp was built specifically to fit in the small spaces of the bones of the hand. It functions well but is limited to use with oblique or
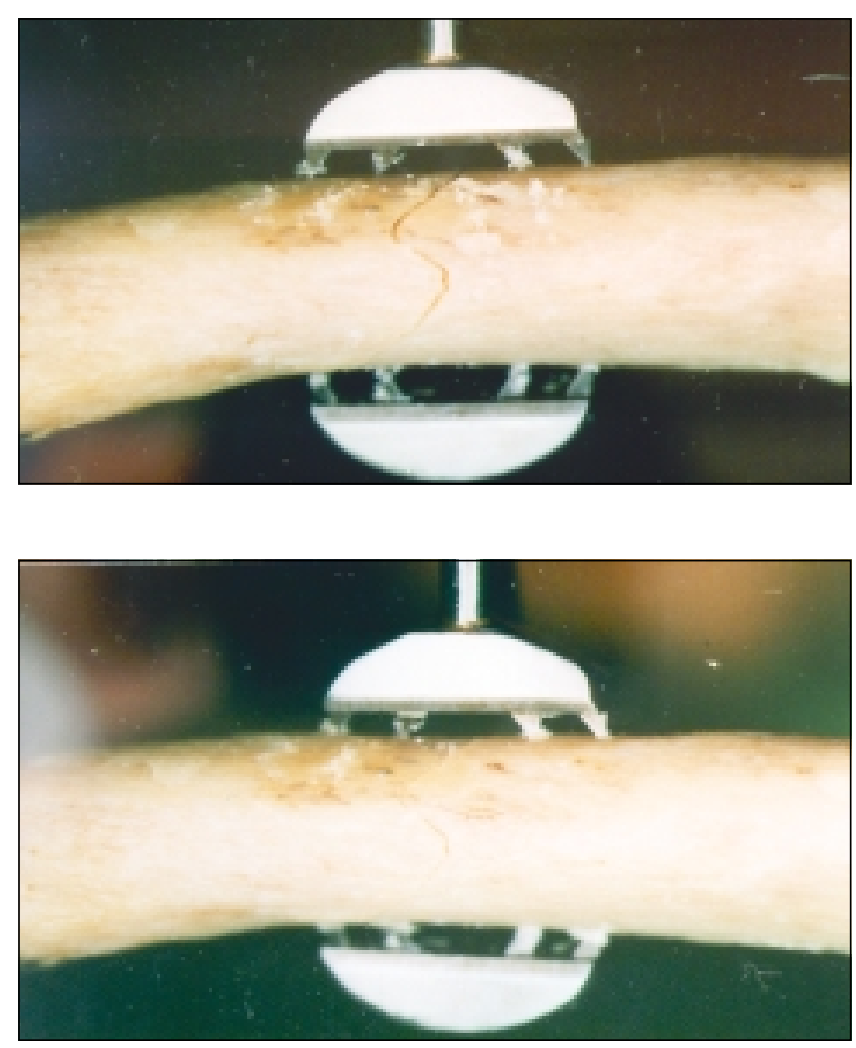

Figure 4) Dynamic compression in a dried human fractured bone. Top The teeth have just barely purchased the bone. Bottom The teeth have purchased the bone as much as they can in this dry human bone and the bone fragments are dynamically compressed

spiral fractures. It was not designed to address the problem of the transverse fracture. The instrument described in the present article also has sharp points like a towel clip, but is designed to reduce the transverse fracture (Figure 1).

\section{MECHANISM OF DYNAMIC COMPRESSION}

Two teeth go into both of the opposite sides of the bone on each side of the fracture. The medial edge of the teeth (the edge facing the fracture) has a sloping, flat, triangular surface that is sharp at the point and broad at the base. As the tooth enters the bone, the broadening, flat surface drives the bone medially toward the fracture as the bone slides down the widening flat surface (Figure 2). The lateral portion of the tooth (the edge facing away from the fracture) is sharp and pointed all the way down from the tip of the tooth to its base. This end cuts into the advancing bone, allowing the bone to advance medially (Figure 3 ).

The more the teeth penetrate the bone, the greater the dynamic compression force. In very hard bone, where the teeth may not penetrate deeply, there may be very little dynamic compression force (Figure 4). In softer bone, where the teeth are able to penetrate more deeply, a greater dynamic compression force occurs. Figure 5 shows the bone clamp penetrating a pencil, simulating its effect in soft bone.

Regardless of the amount of dynamic compression force 


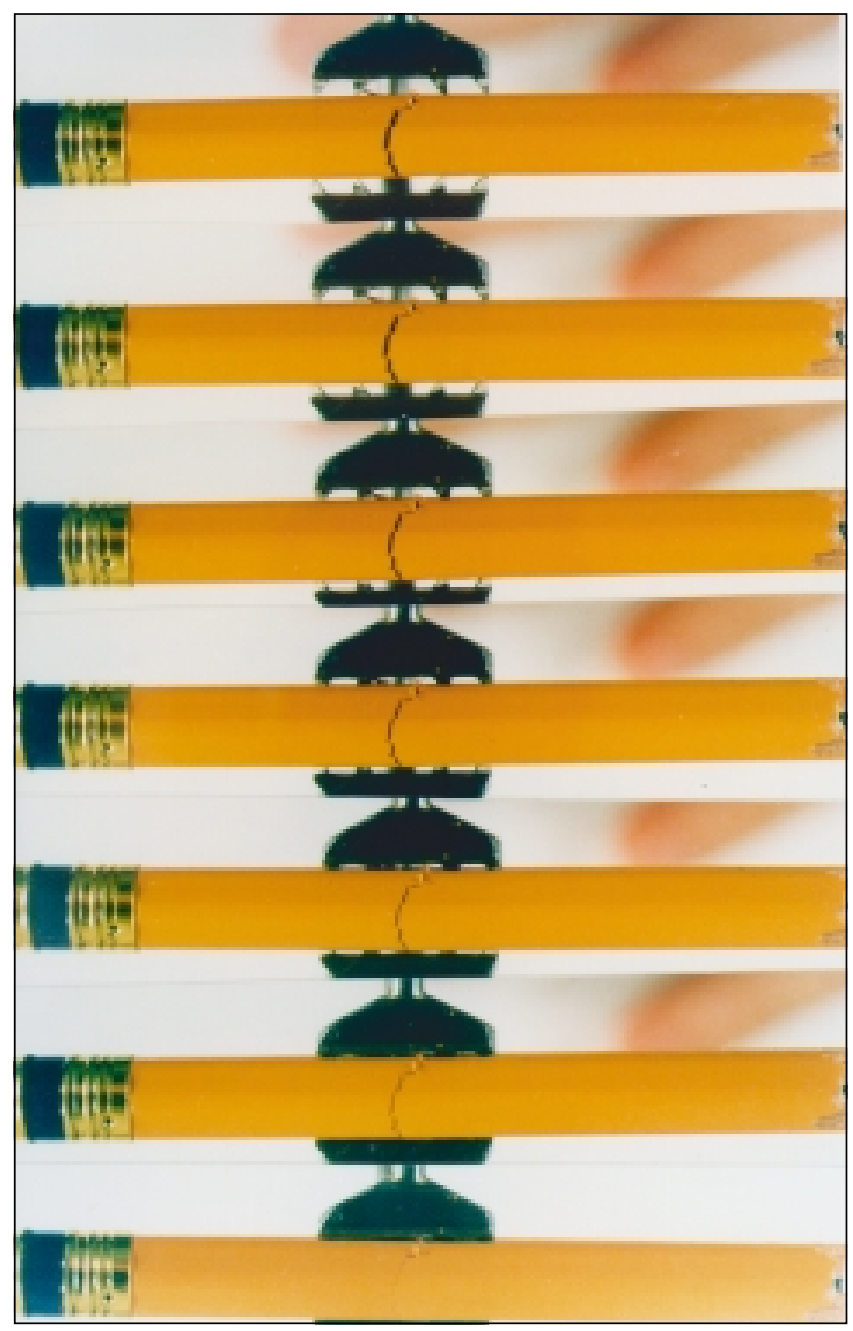

Figure 5) The teeth are just barely penetrating the fractured pencil in the photograph on the top of this time-lapsed photograph figure. As the teeth penetrate progressively deeper to the bottom of the figure, the teeth have penetrated completely and the pencil fracture gap is eliminated

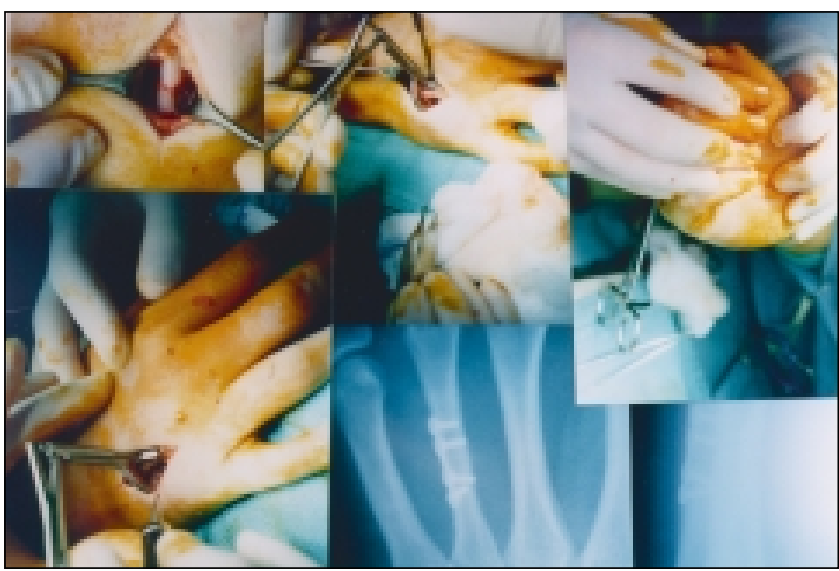

Figure 6) First clinical case in which the dynamic compression bone clamp was used. Top left Fractured metacarpal. Top centre Fracture reduced and the bone clamp applied. Top right Arc of rotation checked with only the bone clamp holding reduction before internal fixation is applied. Bottom left Internal fixation (plate and screws) applied with the bone clamp still in place. Bottom centre and right Postoperative $x$-ray of the same metacarpal

that is applied, the teeth hold the two edges of the transversely fractured bone very firmly so that internal fixation may be applied, and so that the arc of rotation of the fingers can be checked before the internal fixation is applied (Figure 6). In jaw fractures, dental occlusion can be checked while the bone clamp is reducing the fracture, before internal fixation devices are applied.

\section{REFERENCES}

1. Cutting CB, McCarthy JG, Knize DM. Repair and grafting of bone. In: McCarthy JG, ed. Plastic Surgery. Philadelphia: Saunders, 1990:590-2.

2. Lalonde DH. A bone clamp. Can J Plast Surg 1998;6:105-6. 